\title{
The hepatic lipidome and HNF4a and SHBG expression in human liver
}

\author{
Stephen J Winters ${ }^{\mathbb{1} 1}$, Charles R Scoggins ${ }^{2}$, Duke Appiah ${ }^{3}$ and Dushan T Ghooray ${ }^{1}$ \\ ${ }^{1}$ Division of Endocrinology, Metabolism and Diabetes, University of Louisville, Louisville, Kentucky, USA \\ ${ }^{2}$ Division of Surgical Oncology, University of Louisville, Louisville, Kentucky, USA \\ ${ }^{3}$ Department of Public Health, Texas Tech University Health Sciences Center, Lubbock, Texas, USA
}

Correspondence should be addressed to S J Winters: sjwint01@louisville.edu

\begin{abstract}
Low plasma levels of sex hormone-binding globulin (SHBG) are a marker for obesity, insulin resistance, non-alcoholic fatty liver disease (NAFLD) and type 2 diabetes. The transcription $\quad$ SHBG factor HNF4 $\alpha$ is a major determinant of hepatic SHBG expression and thereby serum SHBG $\rightarrow$ HNF4 $\alpha$ levels, and mediates in part the association of low SHBG with hyperinsulinemia and hepatic $\bullet$ fatty acids steatosis. We analyzed the lipidome in human liver specimens from a cohort of patients who underwent hepatic resection as a treatment for cancer, providing insight into hepatic lipids in those without extreme obesity or the clinical diagnosis of NAFLD or non-alcoholic steatohepatitis. Both steatosis and high HOMA-IR were associated with higher levels of saturated and unsaturated FA, other than arachidonic, with the most dramatic rise in 18:1 oleate, consistent with increased stearoyl-CoA desaturase activity. Individuals with low HOMA-IR had low levels of total hepatic fatty acids, while both low and high fatty acid levels characterized the high HOMA-IR group. Both insulin resistance and high levels of hepatic fat were associated with low expression levels of HNF4 $\alpha$ and thereby SHBG, but the expression of these genes was also low in the absence of these determinants, implying additional regulatory mechanisms that remain to be determined. The relationship of all FA studied to HNF $\alpha$ and SHBG mRNAs was inverse, and similar to that for total triglyceride concentrations, irrespective of chain length and saturation vs unsaturation.
\end{abstract}

\section{Introduction}

Sex hormone-binding globulin (SHBG) is a $90-100 \mathrm{kDa}$ homodimeric glycoprotein that transports testosterone and other steroids in the blood plasma, reduces their metabolic clearance, and regulates their access to target tissues (1). SHBG levels are lower with obesity (2) and in patients with type 2 (T2DM) but not type 1 diabetes $(3,4)$, and in those with the metabolic syndrome (MetS) (5). Moreover, a low level of SHBG is associated with an increased risk for developing MetS (6), gestational diabetes (7) and T2DM $(8,9,10)$, and SHBG is often studied as an early biomarker for these disorders (11). In addition, obese, insulin-resistant patients with low SHBG levels often have fatty liver disease $(12,13)$.
However, the mechanism(s) linking low SHBG to these metabolic disorders remains incompletely understood. Early studies established a relationship between hyperinsulinemia and low SHBG (14). Polymorphisms in the SHBG gene (15) and experiments using SHBGtransgenic mice (16) have also implicated SHBG in the pathogenesis of T2DM and NAFLD.

Hepatocyte nuclear factor- 4 (HNF4 $\alpha$ ) is a transcription factor that activates the promoters of multiple genes expressed in liver that function in lipid metabolism (17), and overexpression of HNF4 $\alpha$ increased SHBG transcription in Hep-G2 hepatocarcinoma cells (18), suggesting that hepatic expression of HNF4 $\alpha$ may underlie

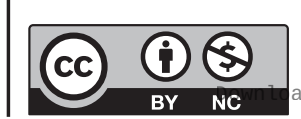

This work is licensed under a Creative Commons Attribution-NonCommercial 4.0 International License. ded from Bioscientifica.com at 04/26/2023 05:03:04AM 
the metabolic associations found with circulating SHBG. Based on those findings, we studied human liver samples, and demonstrated a strong positive correlation between mRNA levels for HNF4 $\alpha$ and SHBG, and found an inverse relationship with the amount of liver triglyceride (19). It is now known that HNF4 $\alpha$ expression is reduced in rodents fed a high fat diet (20), and in liver samples from human patients with NASH (21).

Study of the crystallized ligand-binding domain of rat HNF $4 \alpha$ revealed binding of long-chain FA, which were presumed to represent endogenous ligands (22, 23). Moreover, Hertz et al. found that radiolabeled FA CoA thioesters bound to HNF4 $\alpha$ protein, and that the transcriptional activity of HNF4 $\alpha$ in Cos-7 cells by long-chain fatty acid-CoAs varied by chain length, with activation by C:16 palmitate but suppression by C:18 stearoyl-CoA, while FA shorter than C16 were inactive (24). In other experiments using HepG2 cells, however, palmitoyl-CoA was reported to suppress HNF4 $\alpha$ transcription (25). In the current research, we analyzed the lipidome in human liver specimens from the foregoing patients in order to better understand the relationship between insulin, insulin resistance by HOMA, and hepatic long chain fatty acids and the expression of HNF4 $\alpha$ and SHBG in human liver. We hypothesized that both insulin resistance and total hepatic fat would be associated with lower levels of SHBG mRNA, and based on the results of Hertz et al. (24) there would be a positive association between SHBG mRNA and hepatic palmitate but an inverse relationship with stearate implying a direct role for FA in the control of SHBG expression.

\section{Materials and methods}

\section{Subjects}

Adult men $(n=25)$ and women $(n=23)$ undergoing hepatic resection as treatment for cancer were recruited for this study that was approved by the Institutional Board of the University of Louisville. Their diagnoses included colorectal carcinoma $(n=27)$, hepatocellular carcinoma $(n=7)$, renal cell cancer $(n=3)$ and other $(n=11)$. Subjects were ECOG performance status 0: fully active, and able to carry on all pre-disease performance without restriction. Subjects with other liver diseases, such as hepatitis C, were excluded, as were two women treated with oral estradiol and one with tamoxifen due to marked increases in SHBG. 19 patients had diabetes and 17 were being treated for dyslipidemia. The time from diagnosis to surgery was
1-5 weeks. During this time, there was a median change in weight of $-5 \mathrm{lbs}$ (range -20 to $+10 \mathrm{lbs}$ ). Patients were not instructed to take nutritional supplements before surgery, and no patients received chemotherapy or X-irradiation. Following informed consent, the patient's medical history was reviewed and anthropometric data were collected, and a fasting blood sample was obtained in which glucose was measured in a biomedical panel and an aliquot was frozen at $-70^{\circ} \mathrm{C}$ for the measurement of SHBG and insulin. After surgical resection of the liver specimen, tumor was separated for analysis by the pathologist, and normal liver as distant as possible from the tumor was frozen immediately in an effort to prevent changes due to warming, and stored at $-70^{\circ} \mathrm{C}$ for subsequent study, or was stored in RNAlater (Life Technologies).

\section{RNA isolation and real-time reverse transcription-polymerase chain reaction analysis}

Total RNA was extracted from liver tissue using RNAeasy columns (Qiagen), and analyzed for HNG4 $\alpha$ and SHBG mRNAs by qPCR as described previously (19).

\section{Immunoassays}

SHBG levels were measured with an ELISA kit from ALPCO Diagnostics (Salem, NH, USA). Insulin was measured using an ELISA kit from Mercodia (Winston-Salem, NC, USA).

\section{Lipid profiles}

Tissue was homogenized in diluent $(100 \mathrm{mg} / 0.4 \mathrm{~mL})$ containing $10 \mu \mathrm{L} / \mathrm{mL}$ protease inhibitors (RIPA Lysis buffer, Santa Cruz Biotechnology), and samples were diluted 1:5 for assay. Free fatty acids in the tissue homogenates were analyzed at the Mouse Metabolic Phenotyping Center at the University of Cincinnati (NIH U24 DK059630). Samples were saponified and methylated for gas chromatography analysis. The extracted solution was injected into the GC and retention times were compared to those of known standards.

\section{Data analysis}

Data are presented as the mean \pm S.D. or as the median and interquartile range when continuous variables were not normally distributed or had unequal variance, SigmaStat (San Jose, CA, USA). HOMA-IR was calculated as fasting insulin $(\mathrm{mU} / \mathrm{L}) \times$ glucose $(\mathrm{mg} / \mathrm{dL}) / 405$. Student's $t$-test was used to assess differences between two groups with

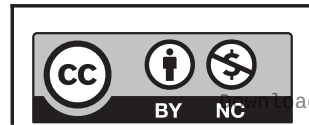

This work is licensed under a Creative Commons Attribution-NonCommercial 4.0 International License. ded from Bioscientifica.com at 04/26/2023 05:03:04AM via free access 
equal variance, and the Mann-Whitney rank-sum test to compare groups when a skewed distribution was found. ANOVA followed by Dunn's test was used to determine differences among multiple groups. Bivariate general linear regression models were performed to determine the association of liver fat chain length/saturation with HNF $4 \alpha$ and SHBG mRNA expression levels. All statistical tests were two-sided and performed at the 0.05 level of significance .

\section{Results}

Normal liver samples surrounding tumor were used to quantitate a spectrum of long-chain fatty acids, and to determine their relationship to expression levels of HNF $4 \alpha$ and SHBG. Liver samples from the individuals in this cohort contained a wide range of FA concentrations. The mean ( \pm s.D.) FA level was $58.1 \pm 55.1 \mathrm{mg} / \mathrm{g}$ liver, with a range of $17.5-251 \mathrm{mg} / \mathrm{g}$. Total fatty acid concentrations were slightly higher in men (median $42.9 \mathrm{mg} / \mathrm{g}$, interquartile range 29.9-80.5) than in women (median $31.3 \mathrm{mg} / \mathrm{g}$, interquartile range (25.3-40.6). Three women and four men had levels $>10 \% \mathrm{FA} / \mathrm{g}$.

Twenty-eight FA was quantified in each sample. Of these, seven FA, three saturated and four non-saturated, accounted for $91.6 \%$ of total FA, and were studied further. The most abundant FA was oleic (18:1) and palmitic (16:0) followed by linoleic (18:2), stearic (18:0), arachidonic (20:4), palmitoleic (16:1) and myristic (14:0) acids (Table 1 ).

Subjects were divided into two groups based on the traditional biochemical diagnosis of steatosis of $>5 \%$ fat content by weight $(n=17)$ or controls $(n=29)$. By this criterion $37 \%$ of this population had steatosis which is comparable to prior estimates by magnetic spectroscopy for United States urban adults (26). As summarized in Table 1 those subjects who met the criteria for steatosis had a higher BMI $(P<0.001)$ and HOMA-IR $(P=0.017)$. The concentrations of myristic, palmitic, stearic, palmitoleic, oleic and linoleic acids were all significantly higher $(P<0.001)$ in those with steatosis while the level of arachidonic acid was similar $(P=0.15)$ in the two groups.

Figure 1 compares the levels of each of the seven FA in the two patient groups as a percent of total liver triglyceride levels. From this perspective, four FA were increased (14:0, 16:0, 16:1 and 18:1) and three were lower (18:0, 18:2 and 20:4) in the steatosis group (all $P<0.001$ ). The most prominent increase was in oleic 18:1, which accounted for $31 \%$ of total FA in the steatosis subjects. The ratios of oleic/stearic, and palmitoleic/palmitic (Table 1) were calculated as indices of stearoyl-CoA desaturase activity (27). Both ratios were higher $(P<0.001)$ in the steatosis subjects, although the fold increase was 3.80 for the 18:0 FA compared to 2.2-fold for the 16:0 FA pair, consistent with the greater activity of stearoylCoA desaturase for stearic than palmitic as substrate,

Table 1 Clinical characteristics and hepatic fatty acid composition in individuals with steatosis compared to the low-fat group.

\begin{tabular}{|c|c|c|c|c|}
\hline & Total cohort $(n=48)$ & $<5 \%$ fat content $(n=32)$ & $>\mathbf{5} \%$ fat content $(n=16)$ & P value \\
\hline Age (years) & $61.8 \pm 11.2$ & $62.6 \pm 11.8$ & $58.9 \pm 9.7$ & 0.29 \\
\hline Sex & $21 \mathrm{~F} / 25 \mathrm{M}$ & 17F/15M & $6 \mathrm{~F} / 10 \mathrm{M}$ & 0.475 \\
\hline $\mathrm{BMI}\left(\mathrm{kg} / \mathrm{m}^{2}\right)$ & $28.9 \pm 6.4$ & $26.6 \pm 5.4$ & $33.2 \pm 6.0$ & $<0.001$ \\
\hline HOMA-IR & $2.49 \pm 2.17$ & $1.99 \pm 0.36$ & $3.62 \pm 0.57$ & 0.017 \\
\hline Total fat (mg/g) & $58.1 \pm 55.1$ & $29.9(25.7-38.1)$ & $98.1(54.0-196)$ & $<0.001$ \\
\hline Myristic $14: 0$ mg/g & $0.78 \pm 1.3^{d}$ & $0.105(0.065-0.23)$ & $1.91(0.61-3.43)$ & $<0.001$ \\
\hline Palmitic $16: 0 \mathrm{mg} / \mathrm{g}$ & $15.5 \pm 17.0^{a}$ & $6.80(5.38-9.34)$ & $31.7(13.8-51.1)$ & $<0.001$ \\
\hline Palmitoleic 16:1 mg/g & $1.75 \pm 2.60^{\mathrm{cd}}$ & $0.28(0.18-0.58)$ & $3.52(1.01-6.90)$ & $<0.001$ \\
\hline Stearic 18:0 mg/g & $4.96 \pm 1.74^{b}$ & $4.08(3.51-4.83)$ & $6.05(5.26-8.50)$ & $<0.001$ \\
\hline Oleic 18:1 mg/g & $16.2 \pm 21.6^{a b}$ & 4.88 (3.57-7.19) & $31.8(15.6-67.9)$ & $<0.001$ \\
\hline Linoleic $18: 2$ mg/g & $10.7 \pm 9.0^{a}$ & $6.42(5.60-7.40)$ & $14.3(10.3-30.5)$ & $<0.001$ \\
\hline Arachidonic $20: 4$ mg/g & $3.31 \pm 0.91^{c}$ & $3.41(2.67-3.87)$ & $2.86(2.38-3.70)$ & 0.151 \\
\hline $16: 1 / 16: 0$ & $0.072 \pm 0.049$ & $0.04(0.031-0.065)$ & 0.095 (0.074-0.145) & $<0.001$ \\
\hline $18: 1 / 18.0$ & $2.63 \pm 2.30$ & $1.23(0.90-1.75)$ & $5.44(3.29-7.57)$ & $<0.001$ \\
\hline SHBG (nmol/L) & $80.4 \pm 51.3$ & $73.4(48.1-96.2)$ & $48.1(35.9-90.9)$ & 0.07 \\
\hline $\begin{array}{l}\text { SHBG mRNA }\left(\times 10^{6}\right) \\
\text { copies/ug RNA }\end{array}$ & $1.04 \pm 0.63$ & $1.05 \pm 0.66$ & $0.79 \pm 0.50$ & 0.048 \\
\hline 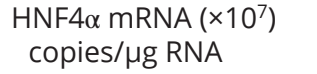 & $1.19 \pm 0.86$ & $1.10(0.68-1.75)$ & $0.97(0.35-1.41)$ & 0.19 \\
\hline
\end{tabular}

Results represent the mean \pm S.D., or the median and interquartile range. FA that share a common superscript are $p=N S$. $P$ values compare subgroup with $<5 \%$ and $>5 \%$ fat content.

https://ec.bioscientifica.com https://doi.org/10.1530/EC-20-0401 (c) 2020 The authors Published by Bioscientifica Ltd

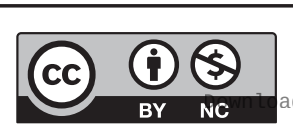

This work is licensed under a Creative Commons Attribution-NonCommercial 4.0 International License. ded from Bioscientifica.com at 04/26/2023 05:03:04AM via free access 


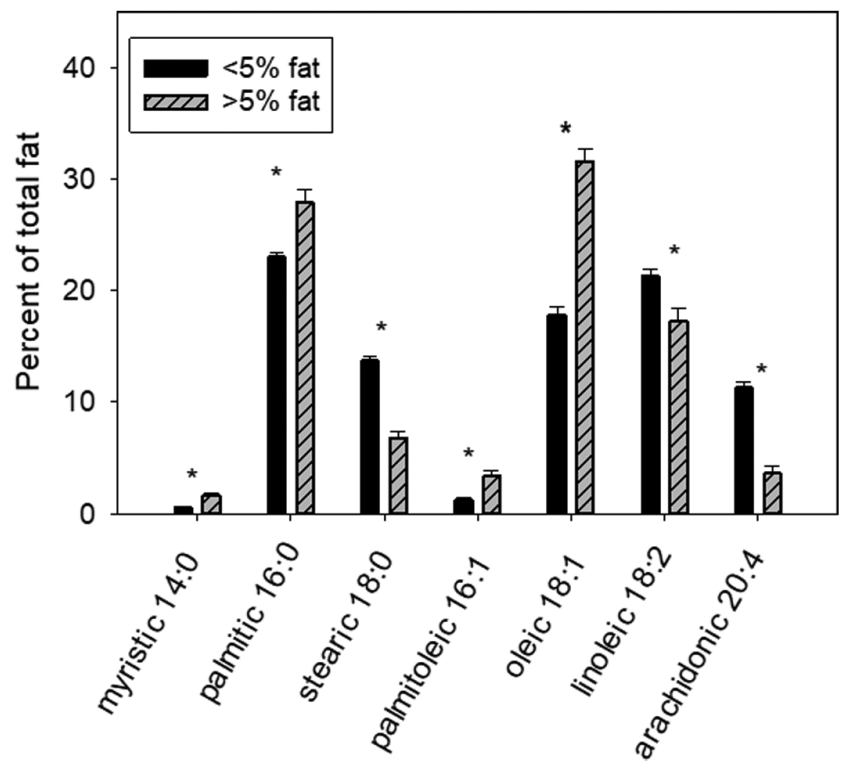

Figure 1

Liver composition of fatty acids represented as percent of total fatty acids measured in individuals with less than or greater than $5 \%$ liver fat. Percent myristic (14:0), palmitic (16:0), palmitoleic (16:1) and oleic (18:1) were higher, while stearic (16:0), linoleic (18:2) and arachidonic (20:4) were lower in subjects with NAFLD. ${ }^{*} P<0.01$.

based on the partially purified enzyme from rat liver microsomes (28).

The relationship between hepatic fat and HOMA-IR is shown in Fig. 2. It is clear that a low HOMA-IR was a determinant of low hepatic triglycerides. On the other hand, the hepatic triglyceride concentration was highly variable in insulin-resistant subjects among

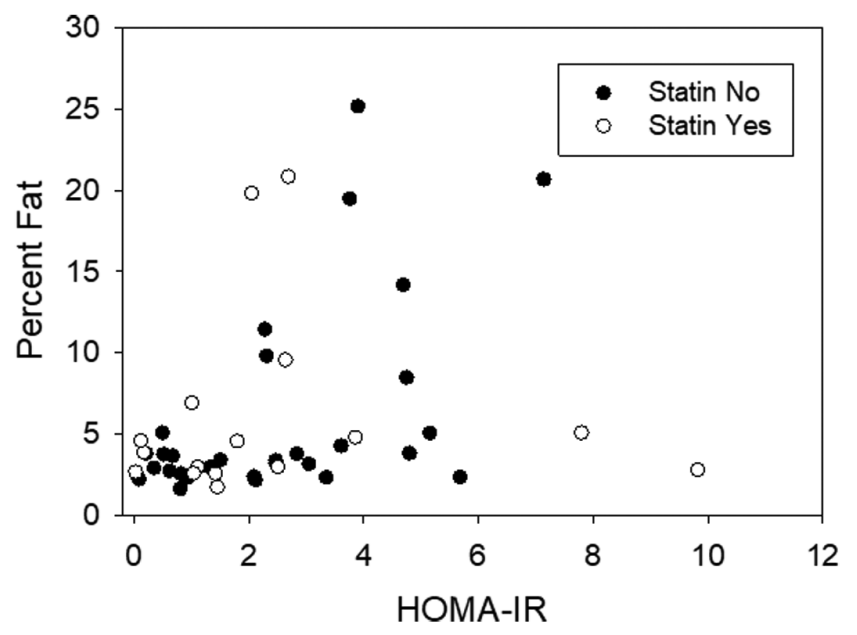

Figure 2

Relationship between percent hepatic fat and HOMA-IR. Subjects being treated with statins are indicated by open circles. Insulin resistance by HOMA-IR was found in the absence or presence of steatosis, whereas total lipid levels were low with insulin sensitivity. whom 6/23 were being treated with a lipid-lowering drug. Nevertheless, total hepatic fat was significantly $(P=0.014)$ greater with insulin resistance when subjects were divided into two groups based on HOMA-IR (Table 2 ). As with the analysis by steatosis, all saturated and unsaturated FA analyzed, other than arachidonic $(20 ; 4)$ were higher in the high HOMA-IR group. The ratios of oleic/stearic and palmitoleic/palmitic were also higher in the high HOMA group, with a higher ratio for the 18 than for the 16 carbon FA pairs. Individuals with high HOMA-IR also had lower levels of SHBG and HNF4 $\alpha$ mRNAs in liver.

Figure 3 illustrates the relationship between SHBG and HNF4 $\alpha$ mRNAs and hepatic triglyceride concentrations for the low HOMA-IR and high HOMA-IR subgroups (A), and with HOMA-IR for those with TGA $<5 \%$ vs $>5 \%$ (B). Subjects with $>50 \mathrm{mg} / \mathrm{g}$ hepatic triglyceride had lower levels of SHBG and HNF4 $\alpha$ mRNAs; however, low mRNA levels were also found in liver without steatosis. Furthermore, most individuals with HOMA-IR $>2.5$ had low SHBG and HNF $4 \alpha$ mRNA concentrations, but low mRNA levels were also found in individuals with HOMA-IR $<2.5$ as well as TGA $<5 \%$.

Each of the lipid signatures was next compared with SHBG and HNF4 $\alpha$ mRNA levels. Figure 4 illustrates the relationships between myristic 14:0, palmitic 16:0, stearic 18:0 and oleic 18:1 with SHBG mRNA. In each case, high FA levels were associated with suppressed SHBG as well as HNF $4 \alpha$ mRNAs, whereas low HNF4 $\alpha$ and SHBG mRNAs were also found in individuals without high levels of these fatty acids. As summarized in Table 3, in unadjusted models, levels of FA of 14-18 carbons were inversely associated with SHBG and HNF4 $\alpha$ expression. In contrast to our initial hypothesis, in each case, irrespective of chain length and saturation vs unsaturation, the relationship to HNF $\alpha$ and SHBG mRNAs was inverse and similar to that for total triglyceride concentrations.

\section{Discussion}

This research examined the relationships between hepatic triglycerides, insulin resistance and the expression levels of SHBG and HNF4 $\alpha$ in surgical human liver samples in part to determine if a unique relationship exists based on fatty acid chain length or saturation. To the best of our knowledge, we also provide the largest quantitative assessment of the human hepatic lipidome for individuals who do not have a clinical diagnosis of NAFLD or NASH, or did not undergo liver biopsy because of extreme obesity

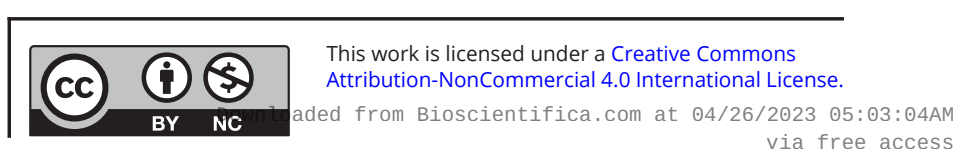


Table 2 Hepatic fatty acid composition, and HNF4 $\alpha$ and SHBG mRNA levels based on HOMA-IR.

\begin{tabular}{|c|c|c|c|}
\hline & \multicolumn{2}{|c|}{ HOMA-IR } & \multirow[b]{2}{*}{$P$ value } \\
\hline & $0.3-2.09(n=23)$ & $2.12-9.82(n=23)$ & \\
\hline & $0.82(0.35-1.42)$ & $3.61(2.51-4.80)$ & 0.001 \\
\hline Total fat (mg/g) & $29.8(25.8-38.8)$ & $48.1(21.8-114)$ & 0.009 \\
\hline Myristic 14:0 mg/g & $0.105(0.065-0.395)$ & $0.598(0.150-2.08)$ & 0.006 \\
\hline Palmitic $16: 0 \mathrm{mg} / \mathrm{g}$ & $6.79(5.23-9.43)$ & $11.7(6.95-39.0)$ & 0.012 \\
\hline Palmitoleic $16: 1 \mathrm{mg} / \mathrm{g}$ & $0.284(0.161-0.700)$ & $1.17(0.747-3.62)$ & 0.002 \\
\hline Stearic $18: 0 \mathrm{mg} / \mathrm{g}$ & $4.12(3.51-5.00)$ & $5.24(3.72-6.70)$ & 0.033 \\
\hline Oleic 18:1 mg/g & $4.88(3.50-9.55)$ & $12.6(6.28-34.0)$ & 0.005 \\
\hline Linoleic $18: 2$ mg/g & $6.42(5.50-8.03)$ & $9.60(6.36-22.6)$ & 0.016 \\
\hline Arachidonic $20: 4$ mg/g & $3.57(2.90-3.91)$ & $2.72(2.45-3.33)$ & 0.047 \\
\hline Oleate 18:1/stearic 18:0 & $1.25(0.90-2.04)$ & $2.65(1.54-6.00)$ & 0.005 \\
\hline Palmitoleic $16: 1 /$ palmitic $16: 0$ & $0.044(0.031-0.067)$ & $0.086(0.051-0.118)$ & 0.002 \\
\hline $\mathrm{HNF} 4 \alpha \mathrm{mRNA} \times 10^{7}$ & $1.64 \pm 0.98$ & $0.80 \pm 0.57$ & 0.001 \\
\hline SHBG mRNA $\times 10^{6}$ & $1.29 \pm 0.59$ & $0.78 \pm 0.61$ & 0.006 \\
\hline
\end{tabular}

Results are mean \pm S.D., or median and interquartile range. Total subjects are 46 due to missing fasting insulin levels.

in conjunction with gastric bypass surgery. We found that both insulin resistance based on high HOMA-IR, and hepatic steatosis, are associated with low HNF4 $\alpha$ and SHBG mRNA levels, but low levels were also found in the absence of these regulators, implying that other mechanisms also lead to suppressed expression of these genes. In addition, neither chain length nor saturation influenced substantially the relationship between long-chain FAs with SHBG or HNF $4 \alpha$ mRNAs. These results extend the findings of Luo et al. (29) and Sáez-Lopez et al. (30), who reported that SHBG mRNA and protein levels correlate negatively with hepatic triglyceride content in patients with benign hepatic tumors or obese patients with NAFLD undergoing bariatric surgery, respectively, and suggest that down-stream signaling by increased hepatic fatty acids, rather than the fatty acid per se, is responsible for the low levels of SHBG in subjects with metabolic syndrome.

This study provides data from a unique patient cohort in which results for subjects fulfilling the traditional criteria for NAFLD of $>5 \%$ hepatic fat were compared to a comparable cohort with $<5 \%$ hepatic fat. The BMI of those with steatosis was significantly higher. Steatosis was not found in subjects with normal HOMA-IR, whereas excess hepatic triglyceride accumulation was found in some but not all those with insulin resistance. Both treatment with statins (31), and the impact of dietary fructose and fat (32), which were not assessed, may have contributed to these results.

As in previous studies $(33,34,35)$, the predominant FA in liver was palmitic (16:0) followed by oleic (18:1) and
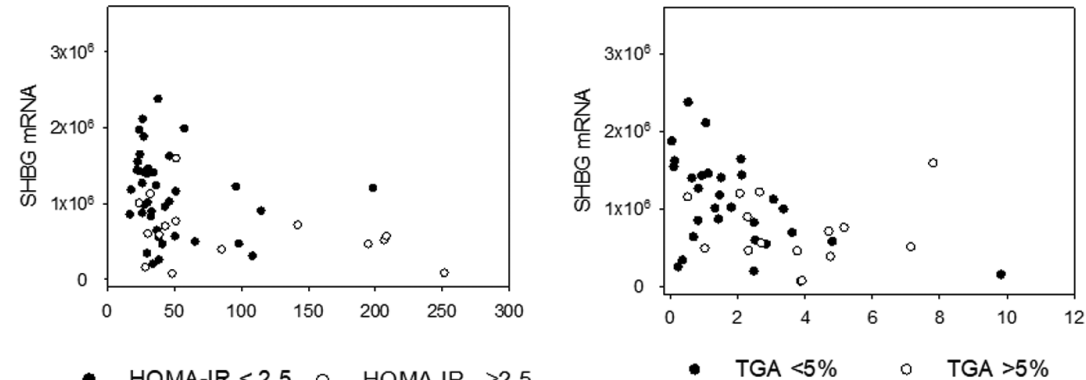

- HOMA-IR $<2.5$ o HOMA-IR $>2.5$
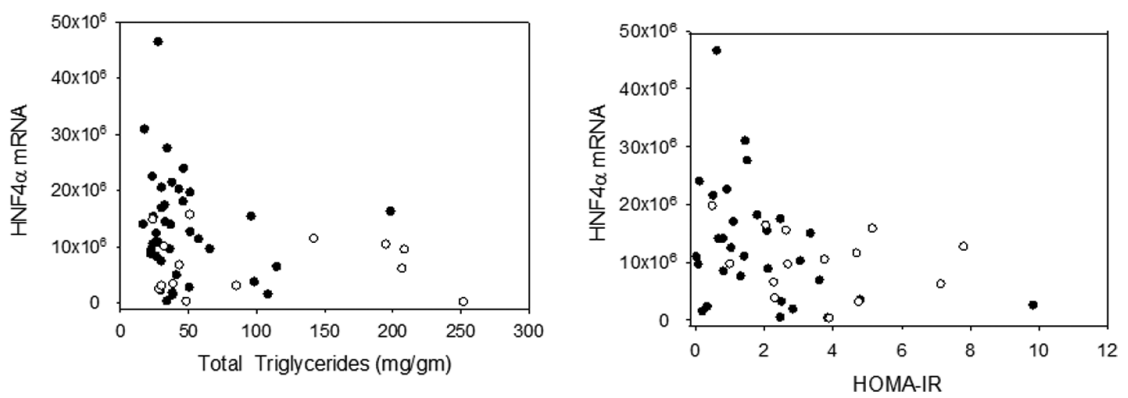

Figure 3

Relationship between total triglycerides and SHBG (A) and $H N F 4 \alpha(B)$ mRNA levels, and between HOMA-IR and SHBG (C) and HNF4 $\alpha$ mRNA (D) levels. In A and B those with HOMA-IR of $<$ or $>2.5$ are noted while in $C$ and $D$ those with hepatic triglyceride of $<$ or $>5 \%$ are shown. There is a curvilinear relationship between these variables, with high HOMA-IR or hepatic triglycerides associated with lower HNF4 $\alpha$ and SHBG mRNAs. It is noteworthy that certain individuals have low SHBG or HNF4 $\alpha$ mRNA levels with $<5 \%$ hepatic triglycerides as well as HOMA-IR $<2.5$. https://ec.bioscientifica.com https://doi.org/10.1530/EC-20-0401 (c) 2020 The authors Published by Bioscientifica Ltd

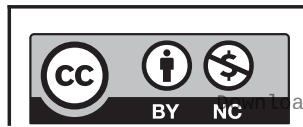

This work is licensed under a Creative Commons Attribution-NonCommercial 4.0 International License. ded from Bioscientifica.com at 04/26/2023 05:03:04AM via free access 

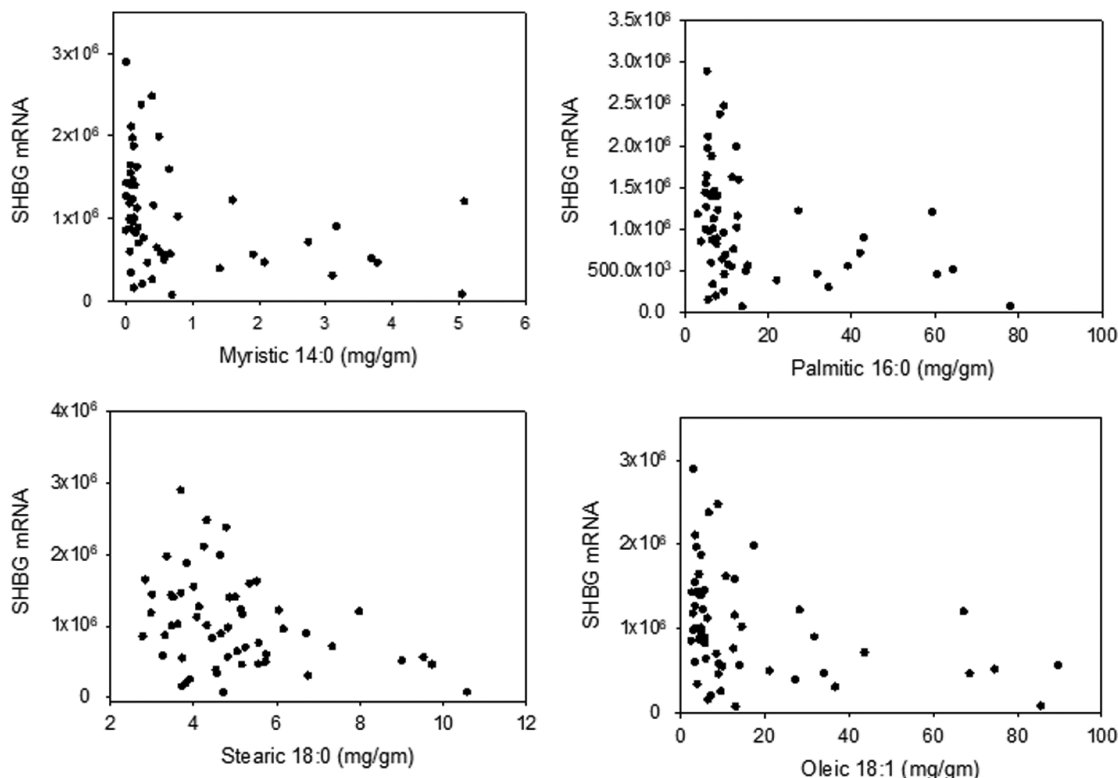

\section{Figure 4}

Relationship between hepatic FA and SHBG mRNA concentrations. Spearman correlation coefficients relating hepatic FA levels to SHBG mRNA were: myristic 14:0 $(r=-0.344 ; P=0.009)$, palmitic $16: 0$ $(r=-0.356 ; P=0.007)$, stearic 18:0 $(r=-0.345$; $P=0.009)$ and oleic $18: 1(r=-0.354 ; P=0.007)$, as well as (not shown) linoleic 18:2 $(r=-0.28$, $P=0.036)$; palmitoleic $16: 1(r=-0.354 ; P=0.007)$ and arachidonic $(r=-0.113, P=0.409)$. Neither type of FA, chain length nor saturation was found to have a unique relationship to the expression level of SHBG. stearic (18:0). The concentrations of myristic, palmitic, stearic, palmitoleic, oleic and linoleic acids were all significantly higher in those with steatosis while the level of arachidonic acid in the two groups was similar perhaps because arachidonic acid is not metabolically determined but rather is derived from the dietary essential linoleic acid through $\Delta 6$-desaturation (36) and is esterified in membrane phospholipids (37). With steatosis, there was a striking increase in oleic 18:1, the product of stearoyl-CoA reductase, which accounted for $31 \%$ of total FFA among the steatosis group.

Because of lipotoxicity (38), several previous studies have carefully examined the spectrum of FA in liver in NAFLD and NASH patients, and controls, but with variable results. Araya et al. (39) studied liver from 19 patients undergoing bariatric surgery (10 with NAFLD and 9 with NASH), and 11 patients undergoing anti-reflux surgery as controls. While total triglycerides and levels of 16:0 and 18:1 were high in NAFLD and NASH subjects, 18:0 and 18:2 were similar while 14:0 and 20:4 were lower in patients than controls. Some subjects had consumed a $25 \mathrm{kcal} / \mathrm{kg}$ diet before the surgery. Puri et al. (33) performed a core needle liver biopsy in individuals diagnosed with NAFLD $(n=9)$ or NASH $(n=9)$. The control group $(n=9)$ was undergoing abdominal surgery with no symptoms or signs of liver disease, but were noted to be obese with the metabolic syndrome. They found increased total lipids, diacyglycerol and triacylglycerol in the NAFLD and NASH groups, but no differences in the levels of individual saturated or non-saturated FFA among their study groups. Allard et al. (34) studied 73 patients undergoing liver biopsy for elevated liver enzymes and suspected NAFLD. Of these, 17 with normal liver biopsies and $<5 \%$ steatosis were designated controls, but they had similar BMI, waist circumference and percent diabetes as those diagnosed with NAFLD by biopsy. They reported FA composition as percent of total FA, and found higher values for 16:1 and 18:1 only in those with NASH, but no difference in 16:0 and 18:0, and like our findings, lower percentage of 20:4 than in those without steatosis. Lukkonenn et al. (40)

Table 3 Relation of liver fat chain length/saturation with SHBG and HNF4 $\alpha$ expression levels.

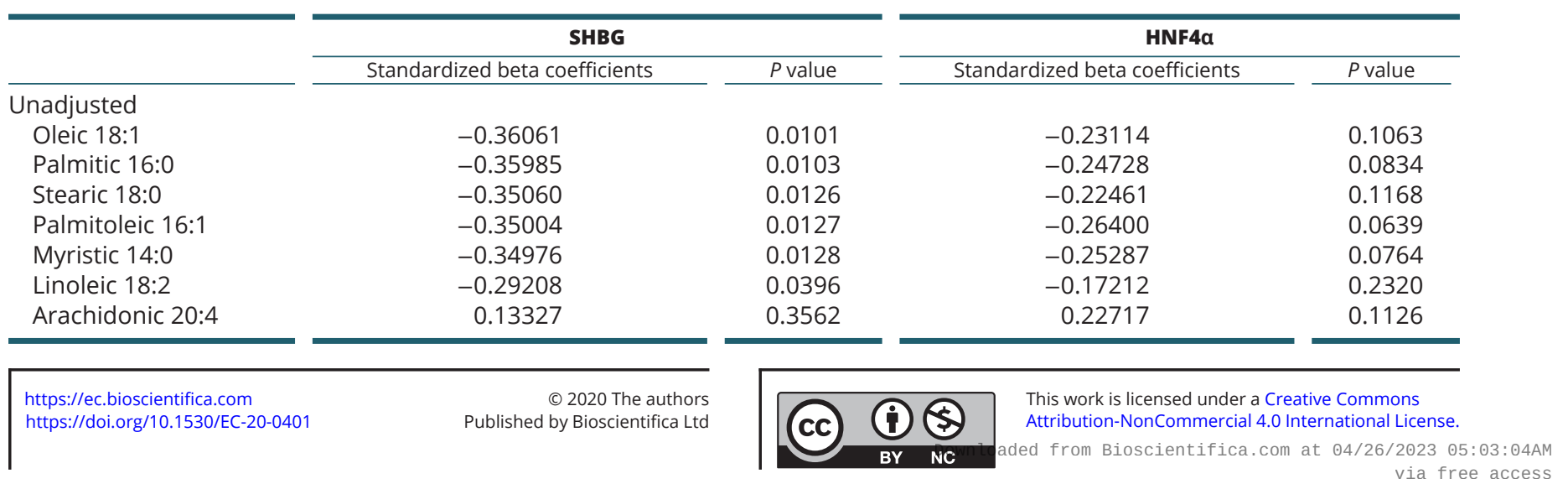


studied 125 adults undergoing laparoscopic bariatric surgery and divided them into low vs high HOMA-IR subgroups. Hepatic concentrations of palmitic, stearic and oleic FA were all statistically higher in the high HOMA group. Kumashiro et al. (35) found higher levels of all hepatic FA measured in subjects with high HOMA-IR, but the numbers of subjects was small (4/group), and the between-group difference were not statistically significant. Not only sample size, but also differences in diet and control groups, as well as methodological details are among the factors contributing to these variable results.

Stearoyl-CoA desaturase (SCD) is the ratelimiting enzyme in the bioconversion of saturated to monounsaturated FA (41). We found a marked rise in oleic 18:1 in our steatosis patients among whom it represented $31.6 \%$ of total hepatic fat. In agreement with the results from Kotronen et al. (42), the ratio of product to precursor 18:1-18:0, as well as 16:1-16:0, as measures of SCD activity, were higher in our subjects with hepatic steatosis, as well as those with high HOMA-IR, with higher values for the 18:1/18:0 pair, the preferential substrate. Stefan et al. (43) did not find up-regulation of SCD-1 expression or activity in subjects with fatty liver or insulin resistance while Peter et al. (44) found that SCD1 mRNA levels in human liver samples obtained at surgery for a variety of clinical conditions were positively associated with the ratio of 16:1-16:0 in the VLDL triglyceride fraction separated by TLC but not with the ratio 18:1-18:0. Our data support the notion that insulin resistance and hepatic steatosis in humans are associated with increased SCD activity.

$\mathrm{HNF} 4 \alpha$ is an orphan nuclear receptor that is a master regulator of liver development and function, including genes involved in triacylglycerol, cholesterol and lipoprotein metabolism $(17,45)$, and is thought to play a central role in fatty liver disease (46). Our results reveal suppressed HNF4 $\alpha$ expression not only with steatosis but also with insulin resistance. While the direction of causality between variables cannot be determined from a cross-sectional study, our results support the notion of a feed-forward mechanism in which hepatic HNF $4 \alpha$ expression is decreased by the steatosis that results from genetically determined insulin resistance in adipose tissue leading to increased plasma and hepatic FA $(47,48)$, and reduced $\mathrm{HNF} 4 \alpha$ expression, together with hepatokines, increase liver fat which worsens insulin resistance (49). This sequence is further amplified inasmuch as $\mathrm{HNF} 4 \alpha$ regulates its own level of expression (50).

Many studies have shown that NALFD in men and women is associated with low serum SHBG levels (51). Fatty acids and their lipotoxic metabolites increase the production of cytokines, including TNF, IL-6 and IL-1b, which initiate the production of pro-inflammatory signals, including nuclear factor- $\kappa \mathrm{B}$ (NFkb) and c-jun n-terminal kinase (JNK) (52). Selva and colleagues, using HepG2 hepatocarcinoma cells, showed that TNF $\alpha$ suppresses SHBG expression by decreasing HNF $4 \alpha$ through a mechanism involving NF- $\kappa \mathrm{B}$ (53), and that IL1 $\beta$ reduces SHBG mRNA through $H N F-4 \alpha$ via the MAPK kinase-1/2 and JNK signaling pathways (54), and we reported a strong positive correlation between the expression levels of HNF $4 \alpha$ and SHBG using the human liver samples in this study (19). We then considered the possibility that fatty acids might also regulate $\mathrm{HNF} 4 \alpha$ and thereby SHBG directly since fatty Acyl CoAs have been reported to stimulate or inhibit $\mathrm{HNF} 4 \alpha$ transactivation depending on chain length and saturation (24). Our findings show, however, that a high fat content in human liver samples is associated with low levels of SHBG and HNF4 $\alpha$ mRNAs irrespective of chain length and saturation.

The association of high HOMA-IR with reduced HNF $4 \alpha$ and SHBG expression in human liver support and extend the association of high insulin or c-peptide levels with low serum SHBG levels in patients (55), and with experimental evidence linking insulin resistance with hyperinsulinemia to low levels of SHBG by suppressing HNF4 $\alpha$. Specifically, Xie et al. (56) showed that HNF $\alpha$ mRNA in liver is decreased in diabetic hyperinsulinemic $\mathrm{db} / \mathrm{db}$ mice but not in mice rendered diabetic by streptozotocin-induced hypoinsulinemia, and that insulin inhibits HNF4 $\alpha$ expression by stimulating transcription of SREBP. Thus both high insulin and hepatic fat downregulate $\mathrm{HNF} 4 \alpha$ and thereby SHBG expression through distinct mechanisms.

Several limitations of the current study should be acknowledged. First, liver samples were obtained from patients with cancer, and although their clinical performance was ECOG grade 0 - fully active - and they had not received chemo- or radiation-therapy, some impact of their cancer diagnosis or self-management is possible. As a cross-sectional correlative study, the direction of causality cannot be proven. Gas chromatography was used to separate and quantify FA, and quantification by mass spectrometry may be more sensitive and accurate (57). While the tissue samples studied were at least $1 \mathrm{~cm}^{3}$ in volume, the lipid content of the liver is not homogeneous, and the distribution of FA differs within lipid droplets and outside of steatotic vesicles (58). DAG within lipid droplets was the strongest predictor of insulin resistance in the study by Kumashiro et al. (35). 
In summary, we describe the distribution of fatty acids in surgical liver specimens from subjects with a wide range of values and insulin sensitivity by HOMA-IR. Because of ethical considerations, most previous studies of human liver have been performed in obese subjects undergoing bariatric surgery or in those with the diagnosis of NAFLD or NASH. Our purpose was to further determine how hepatic FA and insulin resistance might regulate HNF4 $\alpha$ expression in humans, and thereby SHBG, a plasma biomarker for metabolic syndrome, T2DM, and NALFD. We provide evidence that FA and insulin resistance are both important determinants of HNF4 $\alpha$ and thereby SHBG expression, but show that other yet to be discovered factors appear to also cause low SHBG levels. Neither FA side chain length nor saturation altered these relationships.

\section{Declaration of interest}

The authors declare that there is no conflict of interest that could be perceived as prejudicing the impartiality of the research reported.

\section{Funding}

This research was supported in part by a gift from the Walter and Avis Jacobs Foundation. The data in this manuscript were presented in part as an abstract at the 2018 annual meeting of the U.S Endocrine Society, Chicago, IL Abstract 6177.

\section{Acknowledgement}

The authors thank Dr Matthew Cave for helpful comments and suggestions for the manuscript.

\section{References}

1 Hammond GL. Plasma steroid-binding proteins: primary gatekeepers of steroid hormone action. Journal of Endocrinology 2016230 R13-R25. (https://doi.org/10.1530/JOE-16-0070)

2 Glass AR, Swerdloff RS, Bray GA, Dahms WT \& Atkinson RL. Low serum testosterone and sex-hormone-binding-globulin in massively obese men. Journal of Clinical Endocrinology and Metabolism 197745 1211-1219. (https://doi.org/10.1210/jcem-45-6-1211)

3 Birkeland KI, Hanssen KF, Torjesen PA \& Vaaler S. Level of sex hormone-binding globulin is positively correlated with insulin sensitivity in men with type 2 diabetes. Journal of Clinical Endocrinology and Metabolism 199376 275-278. (https://doi. org/10.1210/jcem.76.2.8432768)

4 Goodman-Gruen D \& Barrett-Connor E. Sex hormone-binding globulin and glucose tolerance in postmenopausal women. The Rancho Bernardo Study. Diabetes Care 199720 645-649. (https://doi. org/10.2337/diacare.20.4.645)

5 Laaksonen DE, Niskanen L, Punnonen K, Nyyssonen K, Tuomainen TP, Salonen R, Rauramaa R \& Salonen JT. Sex hormones, inflammation and the metabolic syndrome: a population-based study. European Journal of Endocrinology 2003149 601-608. (https:// doi.org/10.1530/eje.0.1490601)
6 Brand JS, van der Tweel I, Grobbee DE, Emmelot-Vonk MH \& van der Schouw YT. Testosterone, sex hormone-binding globulin and the metabolic syndrome: a systematic review and meta-analysis of observational studies. International Journal of Epidemiology 201140 189-207. (https://doi.org/10.1093/ije/dyq158)

7 Veltman-Verhulst SM, van Haeften TW, Eijkemans MJ, de Valk HW, Fauser BC \& Goverde AJ. Sex hormone-binding globulin concentrations before conception as a predictor for gestational diabetes in women with polycystic ovary syndrome. Human Reproduction 2010 25 3123-3128. (https://doi.org/10.1093/humrep/deq272)

8 Lindstedt G, Lundberg PA, Lapidus L, Lundgren H, Bengtsson C \& Bjorntorp P. Low sex-hormone-binding globulin concentration as independent risk factor for development of NIDDM. 12-yr follow-up of population study of women in Gothenburg, Sweden. Diabetes 199140 123-128. (https://doi.org/10.2337/diab.40.1.123)

9 Haffner SM, Laakso M, Miettinen H, Mykkanen L, Karhapaa P \& Rainwater DL. Low levels of sex hormone-binding globulin and testosterone are associated with smaller, denser low density lipoprotein in normoglycemic men. Journal of Clinical Endocrinology and Metabolism 199681 3697-3701. (https://doi.org/10.1210/ jcem.81.10.8855825)

10 Ding EL, Song Y, Manson JE, Hunter DJ, Lee CC, Rifai N, Buring JE, Gaziano JM \& Liu S. Sex hormone-binding globulin and risk of type 2 diabetes in women and men. New England Journal of Medicine 2009 361 1152-1163. (https://doi.org/10.1056/NEJMoa0804381)

11 Hammond GL, Wu TS \& Simard M. Evolving utility of sex hormonebinding globulin measurements in clinical medicine. Current Opinion in Endocrinology, Diabetes, and Obesity 201219 183-189. (https://doi. org/10.1097/MED.0b013e328353732f)

12 Flechtner-Mors M, Schick A, Oeztuerk S, Haenle MM, Wilhelm M, Koenig W, Imhof A, Boehm BO, Graeter T, Mason RA, et al. Associations of fatty liver disease and other factors affecting serum SHBG concentrations: a population based study on 1657 subjects. Hormone and Metabolic Research 201446 287-293. (https://doi org/10.1055/s-0033-1354369)

13 Lazo M, Zeb I, Nasir K, Tracy RP, Budoff MJ, Ouyang P \& Vaidya D. Association Between endogenous sex hormones and liver fat in a multiethnic study of atherosclerosis. Clinical Gastroenterology and Hepatology 201513 1686-93.e2. (https://doi.org/10.1016/j. cgh.2014.12.033)

14 Pugeat M, Crave JC, Elmidani M, Nicolas MH, Garoscio-Cholet M, Lejeune H, Dechaud H \& Tourniaire J. Pathophysiology of sex hormone binding globulin (SHBG): relation to insulin. Journal of Steroid Biochemistry and Molecular Biology 199140 841-849. (https:// doi.org/10.1016/0960-0760(91)90310-2)

15 Perry JR, Weedon MN, Langenberg C, Jackson AU, Lyssenko V, Sparso T, Thorleifsson G, Grallert H, Ferrucci L, Maggio M, et al. Genetic evidence that raised sex hormone binding globulin (SHBG) levels reduce the risk of type 2 diabetes. Human Molecular Genetics 201019 535-544. (https://doi.org/10.1093/hmg/ddp522)

16 Saez-Lopez C, Barbosa-Desongles A, Hernandez C, Dyer RA, Innis SM, Simo R \& Selva DM. Sex hormone-binding globulin reduction in metabolic disorders may play a role in NAFLD development. Endocrinology 2017158 545-559. (https://doi.org/10.1210/en.20161668)

$17 \mathrm{Lu} \mathrm{H}$. Crosstalk of HNF4 $\alpha$ with extracellular and intracellular signaling pathways in the regulation of hepatic metabolism of drugs and lipids. Acta Pharmaceutica Sinica: B 20166 393-408. (https://doi. org/10.1016/j.apsb.2016.07.003)

18 Janne M \& Hammond GL. Hepatocyte nuclear factor-4 controls transcription from a TATA-less human sex hormone-binding globulin gene promoter. Journal of Biological Chemistry 1998273 34105-34114. (https://doi.org/10.1074/jbc.273.51.34105)

19 Winters SJ, Gogineni J, Karegar M, Scoggins C, Wunderlich CA, Baumgartner R \& Ghooray DT. Sex hormone-binding globulin gene https://ec.bioscientifica.com https://doi.org/10.1530/EC-20-0401 (c) 2020 The authors Published by Bioscientifica Ltd

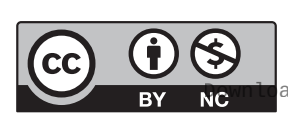

This work is licensed under a Creative Commons Attribution-NonCommercial 4.0 International License. ded from Bioscientifica.com at 04/26/2023 05:03:04AM 
expression and insulin resistance. Journal of Clinical Endocrinology and Metabolism 201499 E2780-E2788. (https://doi.org/10.1210/jc.20142640)

20 Gaballah HH, El-Horany HE \& Helal DS. Mitigative effects of the bioactive flavonol fisetin on high-fat/high-sucrose induced nonalcoholic fatty liver disease in rats. Journal of Cellular Biochemistry 2019120 12762-12774. (https://doi.org/10.1002/ jcb.28544)

$21 \mathrm{Xu} \mathrm{Y,} \mathrm{Zalzala} \mathrm{M,} \mathrm{Xu} \mathrm{J,} \mathrm{Li} \mathrm{Y,} \mathrm{Yin} \mathrm{L} \mathrm{\&} \mathrm{Zhang} \mathrm{Y.} \mathrm{A} \mathrm{metabolic} \mathrm{stress-}$ inducible miR-34a-HNF4 $\alpha$ pathway regulates lipid and lipoprotein metabolism. Nature Communications 20156 7466. (https://doi. org/10.1038/ncomms8466)

22 Dhe-Paganon S, Duda K, Iwamoto M, Chi YI \& Shoelson SE. Crystal structure of the HNF4 alpha ligand binding domain in complex with endogenous fatty acid ligand. Journal of Biological Chemistry 2002277 37973-37976. (https://doi.org/10.1074/jbc.C200420200)

23 Wisely GB, Miller AB, Davis RG, Thornquest AD, Jr, Johnson R, Spitzer T, Sefler A, Shearer B, Moore JT, Miller AB, et al. Hepatocyte nuclear factor 4 is a transcription factor that constitutively binds fatty acids. Structure 200210 1225-1234. (https://doi.org/10.1016/ s0969-2126(02)00829-8)

24 Hertz R, Magenheim J, Berman I \& Bar-Tana J. Fatty acyl-CoA thioesters are ligands of hepatic nuclear factor-4alpha. Nature 1998 392 512-516. (https://doi.org/10.1038/33185)

25 Selva DM, Hogeveen KN, Innis SM \& Hammond GL. Monosaccharide-induced lipogenesis regulates the human hepatic sex hormone-binding globulin gene. Journal of Clinical Investigation 2007117 3979-3987. (https://doi.org/10.1172/JCI32249)

26 Browning JD, Szczepaniak LS, Dobbins R, Nuremberg P, Horton JD, Cohen JC, Grundy SM \& Hobbs HH. Prevalence of hepatic steatosis in an urban population in the United States: impact of ethnicity. Hepatology 200440 1387-1395. (https://doi.org/10.1002/hep.20466)

27 Hodson L \& Fielding BA. Stearoyl-CoA desaturase: rogue or innocent bystander? Progress in Lipid Research 201352 15-42. (https://doi. org/10.1016/j.plipres.2012.08.002)

28 Jeffcoat R, Brawn PR, Safford R \& James AT. Properties of rat liver microsomal stearoyl-coenzyme A desaturase. Biochemical Journal 1977 161 431-437. (https://doi.org/10.1042/bj1610431)

29 Luo J, Chen Q, Shen T, Wang X, Fang W, Wu X, Yuan Z, Chen G, Ling W \& Chen Y. Association of sex hormone-binding globulin with nonalcoholic fatty liver disease in Chinese adults. Nutrition and Metabolism 201815 79. (https://doi.org/10.1186/s12986-018-0313-8)

30 Sáez-López C, Salcedo-Allende MT, Hernandez C, Simó-Servat O, Simó R \& Selva DM. Sex hormone-binding globulin expression correlates With acetyl-coenzyme A carboxylase and triglyceride content in human liver. Journal of Clinical Endocrinology and Metabolism 2019104 1500-1507. (https://doi.org/10.1210/jc.201800740)

31 Athyros VG, Alexandrides TK, Bilianou H, Cholongitas E, Doumas M, Ganotakis ES, Goudevenos J, Elisaf MS, Germanidis G, Giouleme O, et al. The use of statins alone, or in combination with pioglitazone and other drugs, for the treatment of non-alcoholic fatty liver disease/non-alcoholic steatohepatitis and related cardiovascular risk. An Expert Panel Statement. Metabolism: Clinical and Experimental 201771 17-32. (https://doi.org/10.1016/j.metabol.2017.02.014)

32 Softic S, Cohen DE \& Kahn CR. Role of dietary fructose and hepatic de novo lipogenesis in fatty liver disease. Digestive Diseases and Sciences 201661 1282-1293. (https://doi.org/10.1007/s10620-0164054-0)

33 Puri P, Baillie RA, Wiest MM, Mirshahi F, Choudhury J, Cheung O, Sargeant C, Contos MJ \& Sanyal AJ. A lipidomic analysis of nonalcoholic fatty liver disease. Hepatology 200746 1081-1090. (https://doi.org/10.1002/hep.21763)

34 Allard JP, Aghdassi E, Mohammed S, Raman M, Avand G, Arendt BM, Jalali P, Kandasamy T, Prayitno N, Sherman M, et al. Nutritional assessment and hepatic fatty acid composition in non-alcoholic fatty liver disease (NAFLD): a cross-sectional study. Journal of Hepatology 200848 300-307. (https://doi.org/10.1016/j. jhep.2007.09.009)

35 Kumashiro N, Erion DM, Zhang D, Kahn M, Beddow SA, Chu X, Still CD, Gerhard GS, Han X, Dziura J, et al. Cellular mechanism of insulin resistance in nonalcoholic fatty liver disease. PNAS $2011 \mathbf{1 0 8}$ 16381-16385. (https://doi.org/10.1073/pnas.1113359108)

36 Rett BS \& Whelan J. Increasing dietary linoleic acid does not increase tissue arachidonic acid content in adults consuming Western-type diets: a systematic review. Nutrition and Metabolism 2011836. (https://doi.org/10.1186/1743-7075-8-36)

37 Martin SA, Brash AR \& Murphy RC. The discovery and early structural studies of arachidonic acid. Journal of Lipid Research 2016 57 1126-1132. (https://doi.org/10.1194/jlr.R068072)

38 Unger RH. Minireview: weapons of lean body mass destruction: the role of ectopic lipids in the metabolic syndrome. Endocrinology 2003 144 5159-5165. (https://doi.org/10.1210/en.2003-0870)

39 Araya J, Rodrigo R, Videla LA, Thielemann L, Orellana M, Pettinelli P $\&$ Poniachik J. Increase in long-chain polyunsaturated fatty acid n-6/n-3 ratio in relation to hepatic steatosis in patients with nonalcoholic fatty liver disease. Clinical Science 2004106 635-643. (https://doi.org/10.1042/CS20030326)

40 Luukkonen PK, Zhou Y, Sädevirta S, Leivonen M, Arola J, Orešič M, Hyötyläinen T \& Yki-Järvinen H. Hepatic ceramides dissociate steatosis and insulin resistance in patients with non-alcoholic fatty liver disease. Journal of Hepatology 201664 1167-1175. (https://doi. org/10.1016/j.jhep.2016.01.002)

41 Paton CM \& Ntambi JM. Biochemical and physiological function of stearoyl-CoA desaturase. American Journal of Physiology: Endocrinology and Metabolism 2009297 E28-E37. (https://doi.org/10.1152/ ajpendo.90897.2008)

42 Kotronen A, Seppänen-Laakso T, Westerbacka J, Kiviluoto T, Arola J Ruskeepää AL, Oresic M \& Yki-Järvinen H. Hepatic stearoyl-CoA desaturase (SCD)-1 activity and diacylglycerol but not ceramide concentrations are increased in the nonalcoholic human fatty liver. Diabetes 200958 203-208. (https://doi.org/10.2337/db08-1074)

43 Stefan N, Peter A, Cegan A, Staiger H, Machann J, Schick F, Claussen CD, Fritsche A, Häring HU \& Schleicher E. Low hepatic stearoyl-CoA desaturase 1 activity is associated with fatty liver and insulin resistance in obese humans. Diabetologia 200851 648-656. (https://doi.org/10.1007/s00125-008-0938-7)

44 Peter A, Cegan A, Wagner S, Lehmann R, Stefan N, Königsrainer A Königsrainer I, Häring HU \& Schleicher E. Hepatic lipid composition and stearoyl-coenzyme A desaturase 1 mRNA expression can be estimated from plasma VLDL fatty acid ratios. Clinical Chemistry 200955 2113-2120. (https://doi.org/10.1373/ clinchem.2009.127274)

45 Li M, Tang Y, Wu L, Mo F, Wang X, Li H, Qi R, Zhang H, Srivastava A $\&$ Ling C. The hepatocyte-specific HNF4 $\alpha /$ miR-122 pathway contributes to iron overload-mediated hepatic inflammation. Blood 2017130 1041-1051. (https://doi.org/10.1182/blood-2016-12755967)

46 Baciu C, Pasini E, Angeli M, Schwenger K, Afrin J, Humar A, Fischer S, Patel K, Allard J \& Bhat M. Systematic integrative analysis of gene expression identifies HNF4A as the central gene in pathogenesis of non-alcoholic steatohepatitis. PLOS ONE 201712 e0189223. (https://doi.org/10.1371/journal.pone.0189223)

47 Björntorp P, Bergman H, Varnauskas E \& Lindholm B. Lipid mobilization in relation to body composition in man. Metabolism: Clinical and Experimental 196918 840-851. (https://doi. org/10.1016/0026-0495(69)90059-6)

48 Donnelly KL, Smith CI, Schwarzenberg SJ, Jessurun J, Boldt MD \& Parks EJ. Sources of fatty acids stored in liver and secreted via lipoproteins in patients with nonalcoholic fatty liver disease. Journal of Clinical Investigation 2005115 1343-1351. (https://doi. org/10.1172/JCI23621) 
49 Meex RCR \& Watt MJ. Hepatokines: linking nonalcoholic fatty liver disease and insulin resistance. Nature Reviews: Endocrinology 201713 509-520. (https://doi.org/10.1038/nrendo.2017.56)

50 Kyrmizi I, Hatzis P, Katrakili N, Tronche F, Gonzalez FJ \& Talianidis I. Plasticity and expanding complexity of the hepatic transcription factor network during liver development. Genes and Development 200620 2293-2305. (https://doi.org/10.1101/gad.390906)

51 Jaruvongvanich V, Sanguankeo A, Riangwiwat T \& Upala S. Testosterone, sex hormone-binding globulin and nonalcoholic fatty liver disease: a systematic review and meta-analysis. Annals of Hepatology 201716 382-394. (https://doi.org/10.5604/16652681.1235481)

52 Lackey DE \& Olefsky JM. Regulation of metabolism by the innate immune system. Nature Reviews: Endocrinology 201612 15-28. (https://doi.org/10.1038/nrendo.2015.189)

53 Simo R, Barbosa-Desongles A, Lecube A, Hernandez C \& Selva DM. Potential role of tumor necrosis factor-alpha in downregulating sex hormone-binding globulin. Diabetes 201261 372-382. (https://doi. org/10.2337/db11-0727)

54 Simo R, Barbosa-Desongles A, Hernandez C \& Selva DM. IL1beta down-regulation of sex hormone-binding globulin production by decreasing HNF-4alpha via MEK-1/2 and JNK MAPK pathways. Molecular Endocrinology 201226 1917-1927. (https://doi.org/10.1210/ me.2012-1152)

55 Wallace IR, McKinley MC, Bell PM \& Hunter SJ. Sex hormone binding globulin and insulin resistance. Clinical Endocrinology 2013 78 321-329. (https://doi.org/10.1111/cen.12086)

56 Xie X, Liao H, Dang H, Pang W, Guan Y, Wang X, Shyy JY, Zhu Y \& Sladek FM. Down-regulation of hepatic HNF4alpha gene expression during hyperinsulinemia via SREBPs. Molecular Endocrinology 200923 434-443. (https://doi.org/10.1210/me.2007-0531)

57 Alamri H, Patterson NH, Yang E, Zoroquiain P, Lazaris A, Chaurand P \& Metrakos P. Mapping the triglyceride distribution in NAFLD human liver by MALDI imaging mass spectrometry reveals molecular differences in micro and macro steatosis. Analytical and Bioanalytical Chemistry 2019411 885-894. (https://doi.org/10.1007/s00216-0181506-8)

58 Debois D, Bralet MP, Le Naour F, Brunelle A \& Laprévote O. In situ lipidomic analysis of nonalcoholic fatty liver by cluster TOF-SIMS imaging. Analytical Chemistry 200981 2823-2831. (https://doi. org/10.1021/ac900045m)

Received in final form 8 September 2020

Accepted 16 September 2020

Accepted Manuscript published online 16 September 2020
This work is licensed under a Creative Commons Attribution-NonCommercial 4.0 International License. ded from Bioscientifica.com at 04/26/2023 05:03:04AM via free access 